\title{
Deliberative democracy in health care: current challenges and future prospects
}

\author{
This article was published in the following Dove Press journal: \\ Journal of Healthcare Leadership \\ 16 December 2015 \\ Number of times this article has been viewed
}

\author{
Jalil Safaei \\ Department of Economics, University \\ of Northern British Columbia, Prince \\ George, BC, Canada
}

Background: There is a vast body of literature on deliberative, participative, or engaged democracy. In the area of health care there is a rapidly expanding literature on deliberative democracy as embodied in various notions of public engagement, shared decision-making (SDM), patient-centered care, and patient/care provider autonomy over the past few decades. It is useful to review such literature to get a sense of the challenges and prospects of introducing deliberative democracy in health care.

Objective: This paper reviews the key literature on deliberative democracy and SDM in health care settings with a focus on identifying the main challenges of promoting this approach in health care, and recognizing its progress so far for mapping out its future prospects in the context of advanced countries.

Method: Several databases were searched to identify the literature pertinent to the subject of this study. A total of 56 key studies in English were identified and reviewed carefully for indications and evidence of challenges and/or promising avenues of promoting deliberative democracy in health care.

Results: Time pressure, lack of financial motivation, entrenched professional interests, informational imbalance, practical feasibility, cost, diversity of decisions, and contextual factors are noted as the main challenges. As for the prospects, greater clarity on conception of public engagement and policy objectives, real commitment of the authorities to public input, documenting evidence of the effectiveness of public involvement, development of patient decision supports, training of health professionals in SDM, and use of multiple and flexible methods of engagement leadership suited to specific contexts are the main findings in the reviewed literature.

Conclusion: Seeking deliberative democracy in health care is both challenging and rewarding. The challenges have been more or less identified. However, its prospects are potentially significant. Such prospects are more likely to materialize if deliberative democracy is pursued more systematically in the broader sociopolitical domains.

Keywords: citizen juries, patient engagement, shared decision-making, decision aids, public participation

\section{Introduction}

Over the past few decades, a vast body of literature on deliberative, discursive, participative, or engaged democracy and shared decision-making (SDM) has been produced that ranges from conceptual to theoretical, philosophical to ethical, practical to political, experimental to empirical and anything in between. Concurrently, there has been an expanding literature on implications and applications of deliberative democracy in the area of health and health care. Perceptions and interpretations of deliberative democracy in health care are typically couched in various notions of public engagement, SDM,
Correspondence: Jalil Safaei

Department of Economics, University of Northern British Columbia,

3333 University Way, Prince George,

BC V2N 4Z9, Canada

Tel +l 2509606698

Email jalil.safaei@unb.ca 
patient-centered care, patient/care provider autonomy, patient choice or accountable health care, among others.

The sheer volume and diversity of this literature does not yield to a tractable systematic review, nor does it to a scoping review within the scope of a single journal article. Nonetheless, such plentiful and diverse articles provide a rich source of information and evidence as to how deliberative democracy and SDM are conceptualized and understood by various parties involved, how and to what extent it is received by practitioners and patients, how it is facilitated or operationalized, whether or where it works and by what measure, what are the barriers and resistant forces for greater patient involvement, and what are the success stories from which we can learn. To provide some answers to these questions, this study reviews a selected but sizable number of key studies that are frequently cited in the literature related to deliberative democracy and SDM in the health care settings. This rather partial review is mainly concerned with identifying the main challenges and opportunities in the way of promoting deliberative democracy or SDM in the health care systems as identified in previous reviews and other theoretical and empirical studies.

The literature reviewed can be generally divided into several types. Table 1 describes these literature types along with their reference numbers.

For the benefit of readers who are not necessarily familiar with deliberative democracy, the article begins with a brief account of this paradigm by touching on some of the key conceptions and characterization by its proponents in political theory and practice along with some challenges to this paradigm by its critics. Admittedly, such brief introduction can only provide a gist of the conceptions, arguments, debates, and elaborations of the vast literature on deliberative democracy.

Next, numerous conceptions and characterizations of deliberative democracy in health care and medical settings will be reviewed to foreshadow the complexity of understanding and implementing deliberative democracy in health care settings. Such review would give us a broad understanding of the range and depth of specific issues related to patients and professionals' engagement in the deliberation process. After the conceptual review, the empirical literature around

Table I Description of the literature reviewed

\begin{tabular}{lll}
\hline Type of study & Number of studies & Reference number \\
\hline Systematic review & 5 & $70-71,75-76,85$ \\
Scoping review & $\mathrm{I}$ & 77 \\
Environmental scan & $\mathrm{I}$ & 84 \\
Review/overview & 6 & $21,29,86-89$ \\
Conceptual/theoretic & 30 & $5-1 \mathrm{I}, 13,15,44-62,66-67$ \\
Empirical & 13 & $35,39,41,49,94-102$ \\
Total & 56 & \\
\hline
\end{tabular}

the implementation of deliberative democracy in health care settings, and whether they have or have not worked, will be reviewed. In doing so, the article starts by drawing on some of the existing reviews or systematic reviews that often have a particular focus. Then, it will review individual studies that concentrate on specific cases or examples of deliberative democracy or SDM in a particular context using surveys, field observations, informant interviews, and focused groups data. The concrete examples from specific situations would provide a more tangible understanding of the issues surrounding SDM in clinical settings as related to various stakeholders, and the practical lessons that would help promote it. Some of these studies have been examined in the published reviews but not necessarily from the perspective of this review, which is to highlight the current challenges as well as promising developments in seeking deliberative democracy and SDM in the health care settings as identified by each type of the literature.

\section{Conceptions of deliberative democracy in political theory and practice}

Deliberative democracy in its essence is not a new concept. It is perhaps as old as democracy itself, going back to the Athenian democracy during the 6th century BC, where people were directly involved in making some decisions. However, the term "deliberative democracy" in its modern conception is said to have been first used by Bessette in 1980 in an interpretation of the US constitution. ${ }^{1}$ The core of deliberative democracy is considered to be authentic deliberation and consensus decision-making, which can happen in both direct (participative) and representative (delegated) democracies, giving rise to the notions of populist and elitist deliberative democracy, respectively. ${ }^{2-4}$ Many political theorists have elucidated the characteristics of deliberative democracy. For instance, Fishkin considers the following five characteristics to be essential for legitimate deliberation: 1) availability of relevant and accurate information to all participants; 2) substantive balance of different positions based on evidence; 3 ) diversity of positions relevant to the matter; 4) conscientious consideration of all arguments; and 5) equal consideration of views as weighed by evidence. ${ }^{5}$ Cohen also recognizes plurality of views and values in reasonable and respectful deliberation as a source of legitimacy and institution building as an ongoing process. ${ }^{6}$ Others like Gutmann and Thompson emphasize the binding nature of deliberated decisions to all parties involved and require that such decisions be provisional and open to change. ${ }^{7}$

Proponents of deliberative democracy speak to various advantages of deliberated decisions over alternatives. They 
include easier incorporation of scientific opinion and research findings for evidenced-based decisions, greater impartiality and rationality, and moral legitimacy. ${ }^{8}$ Others speak to the virtues of the deliberative process such as learning to respect and be more tolerant of opposing views, achieving greater consensus and social cohesion, greater commitment to decisions, and knowing that participants' views do impact the society. Still others consider it to be better suited to deal with the problems of social choice theory - namely, the arbitrariness of decision rules and vulnerability to strategic voting - compared to liberal democracy, which is characterized as a model for aggregating preferences. ${ }^{9}$

The critics of deliberative democracy are not convinced of the above-mentioned advantages. For example, Blattberg raises four criticisms against deliberative democracy: 1) its support of a theory or a systematic set of procedures for conversation distorts its practice; 2) it is ideologically biased; 3 ) its distinction between conversation and negotiation is overstated; and 4) its conception of the political community, in particular, of the proper relations between the state and civil society, is impoverished. ${ }^{10}$

Most of the critics question the practical feasibility of deliberative democracy in our current societies. For example, Ryfe examines many of the impediments for deliberative practice in his review of the literature. He divides up the deliberative process into three "moments" of 1) the organization of a deliberative encounter; 2) the practice of deliberation within an encounter; and 3 ) the product of deliberative talk. ${ }^{11}$ Problems of self-selection and consequent homogeneity, and time-consuming representative selection with predisposed views are noted as organizational problems that undermine the deliberative process. ${ }^{11}$ Lack of motivation on the part of many to go beyond their "routine scripts" and engage in disrupting dialog, and the tendency of the participants to rely on "information cues" or "shortcuts" to arrive heuristically at a decision, rather than evaluating all the relevant information impede the practice of real deliberation. According to Ryfe, researchers have found three conditions that motivate individuals to "adopt a deliberative frame of mind": accountability, high stakes, and diversity. ${ }^{11}$

With regard to the third moment, the product of deliberative talk, Ryfe, drawing on Warren's work, ${ }^{12}$ refers to a structural ambivalence in deliberative theory with respect to how the deliberative process is supposed to affect policy decisions. Linking the outcome of deliberation with the existing political system is seen as a daunting task as the views and expectations of the policymakers are usually different from those who would see deliberation as the only legitimate basis for policy decisions. ${ }^{11}$
Many of the pragmatic problems of deliberative democracy are traced back to the validity of the assumptions on which deliberative theory rests. For instance, Sanders argues that deliberative democracy in its normative approach abstracts from the reality of people and their behavior and its pursuit of consensus and "common ground" sidesteps individual or group interests, especially those of women, Blacks, and those with lower socioeconomic status. ${ }^{13}$

In response to the above challenges, key deliberative theorists have come to view the development of deliberative democracy to be incremental and happening in phases. In the first phase, the focus is said to have been developing the "ideal proceduralism" of deliberation and recognizing the idea of legitimacy at the core of deliberative democracy. ${ }^{14}$ The second phase is seen as the proliferation of empirical studies and practical applications of the theory, when many deliberative democrats using the ideal image tried to apply deliberative democracy in concrete real-world situations as much as possible. ${ }^{15}$ In doing so, theorists, activists, and government officials collaborated to bring about many new forms of deliberative forums such as citizen juries, consensus councils, people's parliaments, citizen assemblies, and other representative "minipublics" to promote deliberation. ${ }^{16}$ This empirical approach provided the opportunity to evaluate the specific settings and conditions that would enable or constrain deliberative processes. ${ }^{17}$ Mansbridge et al believe that the literature on deliberative democracy has reached a point to begin a third phase, where a "systemic" approach to deliberative democracy is both possible and desirable. ${ }^{14}$ In this approach, the focus is said to be not on individual processes or institutions, but on the interdependence and interaction of a variety of venues and institutions. The systemic approach is seen to:

[...] illuminate not only the more familiar and obviously deliberative practices in a system, but also the value and disvalue of nondeliberative practices that have often been considered antithetical to deliberative democracy. ${ }^{14}$

Mansbridge et al argue that:

[...] a systemic approach allows us to see more clearly where a system might be improved, and recommend institutions or other innovations that could supplement the system in areas of weakness. ${ }^{14}$

However, they recognize five pathologies: tight-coupling and decoupling of parts of the system, institutional domination, social domination, and entrenched partisanship - which may undermine the deliberative system. ${ }^{14}$ 


\section{The advent and conceptions of deliberative democracy in health care} Formal advocacy

Recognition of the rights of citizens or lay people for participation in health care planning, policy development and implementation dates back to at least late 1970s when such rights were formally articulated in a key World Health Organization document, the Alma Ata Declaration, in 1978. The declaration acknowledges that "people have the right and duty to participate individually and collectively in the planning and implementation of their health care". ${ }^{18}$ Such recognition has been reaffirmed in subsequent World Health Organization documents and reports, and many democratic governments in developed countries in Europe, North America, and Australia and New Zealand have made public and user involvement in health care priority setting, service development, and delivery of health care part of their official agendas. ${ }^{19,20}$ In the UK, the government's push for patient/public involvement has been most enduring. ${ }^{20,21}$ The National Health Services (NHS) as the dominant publicly owned and operated health care system has undertaken many policy initiatives, guides, directives, and policy measures to encourage patients and the general public in decision-making in planning, management and provision of various health care services. ${ }^{22-25}$ Similar measures have been taken in other European countries (such as Denmark, Finland, the Netherlands and Sweden) to involve public participation in health care decision-makings (Nolte and Wait, unpublished data, 2005). ${ }^{26,27}$ In the US, efforts to engage the public and patients in health care are rather recent. Washington State was the first state that passed legislation to promote SDM in 2007 with several other states following the lead of Washington with legislations underway. ${ }^{28}$ More recently, attention to SDM and development of decision aids or supports has been emphasized as part of the provisions of Patient Protection and Affordable Care and the Health Care and Education Reconciliation Acts (both enacted in 2010 by the Federal Government) to reform the delivery of health care. ${ }^{28}$ At the same time, there is a proliferation of nonprofit, for-profit, and academic organizations that are engaged in developing various decision aids to help SDM in primary care and clinical settings. ${ }^{28}$ In Canada, where provincial governments are responsible for planning and delivery of health care services, efforts to reform the system for greater public or community participation have been initiated through devolution of authority for decision-making from the provincial governments to regional, district, or local bodies. ${ }^{29,30} \mathrm{~A}$ national initiative was undertaken by the Romanow Commission with the explicit approach to elicit the views of the ordinary "unorganized" citizens about the future of health care in Canada using the "ChoiceWork dialogue" method. ${ }^{31}$ Similar attempts have been underway in Australia to improve public participation in the health care system. ${ }^{32,33}$

Governments' proclamations for fostering user and public involvement are often based on expectations of improvement in the quality of care, greater responsiveness of services to patients' needs and wishes, and more accountability on the part of providers and managers. ${ }^{34-36}$ For instance, Tenbensel identifies two broad and interrelated rationales for public involvement. The first one being mainly concerned with the democratic legitimacy of policy processes, in general, and health policy in particular. And the second rationale being more focused on the contention that public input produces better and more intelligent health policy decisions. ${ }^{37}$ However, other commentators are more cynical about the real intentions of the governments. ${ }^{38-41}$ They see this as an instrumental approach by the governments to seek public legitimacy for their cost containment and rationing measures. Commenting on the experience of priority setting in Europe, Saltman and Figueras note:

The need for public involvement is closely linked to the need to legitimize rationing decisions. This cannot be done by arguing that these decisions are correct, since there can be no right answer to questions about health care priorities [...] Legitimacy, therefore, is derived from the decision-making process. This process is more likely to be seen as legitimate if it is open, if it enables different interests to contribute. ${ }^{42}$

Notwithstanding the various perspectives on the reasons as to why public input or participation is sought, patient and public participation is now pervasive in health care. The article now turns to a discussion of the most well known conceptions and characterizations of deliberative democracy in health care.

\section{Conceptions and elaborations of patient/public participation}

The conceptions and characterization of deliberative democracy in health care are directly or indirectly informed by the conceptions and characterizations of the same in political theory and practice. In this section, the most common conceptions are reviewed, and the explicit or implicit assumptions underlying the various conceptions are discussed. As well, some of the unique features of the health care settings that are more challenging to the idea of deliberation, as well as those that are more receptive and promising, are articulated. 
The term "deliberative democracy" is not used as often in the literature related to health care settings. However, its conception and meaning as variously understood is captured in a number of frequently used descriptive terms. The health care system is often characterized as a complex, multifaceted, and dynamic system that includes multiple stakeholders and is engaged in a variety of decisions ranging from high-level priority setting and fiscal allocations to critical and urgent clinical decisions with immediate impacts on people's lives. Consequently, there are various contexts, levels, and capacities in which people can be involved with the health care system. People may participate in health care decisionmakings in various roles as taxpayers, community members, and/or patients. ${ }^{39}$

Participation of the general public (as citizens) in health care is variously captured in the literature with terms such as "community participation", "public participation or involvement", "lay participation", "user involvement", or "public input". Participation of the patients is commonly captured by the terms: "patient engagement", "patient participation", "patient involvement", "patient collaboration", "patient partnership", "patient-centeredness", "informed consent", "shared decision-making", and "patient autonomy". There is no presumption that these terms are synonymous as they have emerged within different contexts, conceptualized from different perspectives, and laden with normative disciplinary connotations as applied to health care. As a result, there have been many modeling attempts to place them in hierarchies that rank various levels of patient/public involvement along some continuum of intensity or dimension.

Since the pioneering work of Arnstein on the typology of citizen participation, which was presented as an eight-rung ladder ${ }^{43}$ where lower rungs depict "non-participation", the middle rungs indicate "degrees of tokenistic" participation, and the upper rungs show "degrees of citizen power", numerous researchers have suggested either simpler or more nuanced and often less critical hierarchical models of public or patient participation in health care decision-making. For instance, Finegold suggests a framework in which five degrees of participation in the ascending order of citizen/ patient control is distinguished: informing, consultation, partnership, delegated power, and citizen control. ${ }^{44}$ Focusing on the physician-patient relationship Emanuel and Emanuel outline four "Weberian ideal types" of relationships: paternalistic, informative, interpretive, and deliberative. ${ }^{45}$

Similarly, Cahill performs a concept analysis of patient participation from a nursing perspective and suggests a three-level hierarchical relationship between the concepts "patient partnership", "patient participation", and "patient involvement/collaboration" in which patient partnership implies the highest level of participation, and patient involvement/ collaboration signifies the lowest level of participation. ${ }^{46}$ Also Hanley et al distinguish a hierarchy of involvement of the public in the NHS in the UK that elevates from "consultation" to "collaboration" to "user-controlled". ${ }^{47}$

More recently, Thompson proposes a taxonomy of patient involvement and participation along the continuum of patient power. He identifies five degrees of participation associated with the level of patient power: informed decision-making, SDM, professional-as-agent, paternalism (consultation and information-giving), and exclusion (no participation) in the descending order of patient power. ${ }^{48}$

Some researchers have gone beyond the dimension or continuum of power and control to conceptualize other dimensions of patient or public participation. For example, Charles and DeMaio suggest a more extensive participation framework in which three dimensions of domains, roles, and levels are considered. Domains refer to the issues to be decided in which three subcategories of 1) treatment of individual patients; 2) service delivery for a defined region or a particular health facility; and 3) macro health care policies are recognized. The roles dimension is categorized as a user or a member of public; and levels capture the degree of power or control given to the lay people, categorized into "consultation", "partnership", and "lay control". ${ }^{49}$ Also, Forbat et al identify four models of involvement by recognizing four different roles for the patient/partner (as consumer, citizen, partner, and researcher) involved, respectively, in four types of activity (purchasing or choosing service, policy and service planning, care practice, and coresearch). Each of the four models is considered to have its own respective "ideological driver" - namely, Free-market economics, Social-democratic, Experiential knowledge, and Emancipation and empowerment. ${ }^{20}$ Focusing on the patients, some researchers have divided the participation process into "Problem-Solving" and "Decision-Making" stages to reconcile the professional ability of the providers with the patients' preferences. ${ }^{50,51}$

In their critique of the Arnstein's model Tritter and McCallum, point out several weaknesses of that model as being one-dimensional, simplistic, adversarial, and unhelpful for developing and sustaining public or user involvement. ${ }^{52}$ They call for considering "multiple ladders" to reflect the diversity of users and contexts with "bridges" between them to relate the dimensions and allow for "horizontal accountability". They propose a nonhierarchical "mosaic" model that "captures interactions between individual users, their communities, 
voluntary organizations and the health care system on which successful user involvement depends". ${ }^{52}$ Responding to the call for considering multiple ladders or dimensions, Marent et $\mathrm{al}^{53}$ draw on the Luhmann's work ${ }^{54}$ on system theory, to conceptualize a framework where the form of lay participation is considered along three dimensions of social, factual, and temporal. The social dimension is about the distribution of power as in previous categorizations. However, the factual dimension recognizes the mutual exchange of knowledge and experience that expands the range of topics and their definitions. The temporal dimension aims to capture the dynamic process of participation and the various phases this might entail. ${ }^{53}$ Dividing the decisions in the health care organizations into "operative" and "management" levels, and considering the organizations in their surrounding "environment", Marent et al are able to identify four groups of participants - namely, individual patients, patients' significant others, patient groups, and community - that are involved at different levels of decision-making either within or outside of the health care organizations. ${ }^{53}$ Also, a multidimensional framework for patient and family engagement in health and health care has been proposed by Carman et al in which three levels of engagement (direct care, organizational design and governance, and policy-making) are examined across a continuum of engagement that ranges from consultation to involvement to partnership and shared leadership. ${ }^{55}$

\section{Shared decision-making as manifestation of deliberative democracy in health care}

Among the various conceptions and models of patient participation in health care, SDM (and to a lesser extent patient-centered care) models are perhaps the closest to the ideal type of deliberative democracy in terms of meaningful and respectful engagement. SDM is believed to play a key role in the path to evidenced-based clinical practice ${ }^{56}$ and has been recognized as the "pinnacle" of patient-centered care. ${ }^{57}$ A report from the Secretary of State in the UK makes the pronouncement that "Patients must be at the heart of everything we do, not just as beneficiaries of care, but as participants in shared decision making". ${ }^{58}$ In the same vein, it is suggested that "For both payers and regulators, SDM offers an opportunity for them to be on the side of the people". ${ }^{28}$

Over the years, many researchers have invoked or advocated for SDM between patients and physicians regarding treatment decisions. In doing so, they have also tried to bring greater clarity on the concept of SDM and its requirements. For example, Charles et al suggest four key characteristics for SDM in the context of a life-threatening disease with several treatment options: 1) that at least two participants (a physician and a patient) be involved; 2) that both parties share information; 3 ) that both the parties take steps to build a consensus about preferred treatment; and 4) that an agreement is reached on the treatment to be implemented. ${ }^{59}$ However, in view of the different and changing preferences of patients and physicians over time, they caution against standardization of the process and being prescriptive about specific behaviors in the process. As they note, "shared decision-making is in some sense a matter of perception". ${ }^{59}$ In a subsequent work, Charles et al revisit their conceptualization and expand on it by explicitly recognizing three steps involved in the treatment decision-making process (information exchange, deliberation, and deciding on the treatment to implement) and adopting a dynamic and flexible view of the treatment decision-making. ${ }^{60}$ Similarly, Legare and Wittman describe three essential elements of SDM: recognizing and acknowledging that a decision is required, knowing and understanding the best available evidence and incorporating the patient's values and preferences into the decision. ${ }^{61}$ To empower the patients to be able to make critical decisions in rather complicated situations, interested clinicians and advocates of SDM have recognized the need for developing and implementing various decision aids and instruments. ${ }^{62-64}$ However, in a relatively recent review of literature related to SDM, Moumjid et al find that only approximately one-third of them cite a proposed definition of SDM as provided by Charles and colleagues. ${ }^{60}$ Most of the studies refer to the term without specifying or citing a definition, or use it inconsistently with their definition. ${ }^{65}$ Moreover, in an analysis of the SDM models, Stacey et al find that very few consider an interprofessional perspective on decision-making. They observe:

Although some conceptual models identify others beyond the patient-physician dyad, there is no description of the process by which these others (eg, family members, other professionals) are engaged in the decision-making process. ${ }^{66}$

Redefining and refining the notions of participatory and SDM in its various aspects have helped delineate the essential dimensions of participation, that is, goals, roles, issues, and levels of participation as responses to the basic questions of why?, who?, what?, and how?, respectively. ${ }^{53}$ At the same time, the plethora of terms and conceptions related to patient/public participation or involvement in health care is said to have created confusion, so much so that a commentator concludes:

One of the greatest barriers to truly integrating patient involvement into the health service, policy and research is 
the conceptual muddle with which involvement is articulated, understood and actioned. ${ }^{20}$

However, on balance, the evolving literature on the conceptualization of patient/public participation has brought about greater specificity that is hoped to guide empirical examination and assessments of such participation and encourages effective policy-making. But we are cautioned that health care is "a tough testing ground of the ability of any deliberative process to handle legitimacy deficits" ${ }^{67}$ This is in part due to the complexity of the system, asymmetry of power and information, entrenched interests, high stakes, and medical urgencies.

\section{Evidence on the implementation of deliberative democracy in health care}

The implementation of deliberative democracy and SDM in health care settings has taken various forms and methods, which are borrowed from other areas of civic engagement and public participation. They are categorized into broad grouping of methods that include citizens' juries, planning cells, deliberative polling, consensus conferences, and citizens' panels. ${ }^{68}$ This section begins with the review of the empirical evidence on the implementation of deliberative democracy (in its various conceptions) by first reviewing a number of main systematic reviews in this regard.

\section{Evidence from existing (systematic) reviews}

By early 2000s, there had been a sizable number of studies concerned with the implementation of patient or public involvement in specific health care settings, which have been examined in a number of systematic reviews. For instance, Crawford et al review 42 studies that report on the effects of patient involvement in planning and delivering health care. ${ }^{69}$ They find that the studies often describe favorable changes to services such as producing new and improved information for patients and providing more accessible services including simplifying appointment procedures, extending opening times, improving transport to the treatment units and improving access for people with disabilities. They also find from several reports that the staff attitudes became more favorable to involving patients. However, they find that few studies saw patient involvement being used to "legitimize decisions that would have been made whether or not patients supported them" ${ }^{69}$ Overall, the review concludes that beyond reporting some favorable changes in services and attitudes, the studies do not examine the effects of involvement on accessibility, acceptability of services, or the impact on the satisfaction, health or quality of life of patients.
Abelson et al do a critical systematic review of participation literature in English and in French since 1996 including empirical studies of public participation and theoretical and conceptual frameworks with an emphasis on design and evaluation. ${ }^{70}$ They find that only one empirical study attempted to systematically evaluate the use of citizens' jury in health settings, and no study has rigorously compared different participation methods. Drawing on the evaluation frameworks of Renn, ${ }^{71}$ Webler $^{72}$ and Beierle ${ }^{73}$ which were developed for environmental studies, they identify four key components for evaluation of deliberative processes: 1) representation; 2) the structure of the process or procedures; 3) the information used in the process; and 4) the outcomes and decisions arising from the process. The latter are used to develop a set of general principles for the design and evaluation of public participation processes. ${ }^{70}$ Applying those principles to deliberative exercises in health care, they find numerous challenges including:

1. How to mitigate strong vested interests, which may try to use deliberative process to sway the discussion or, ultimately, the outcome of the exercise.

2. How to mitigate potential biases introduced in witness and information selection and presentations due to the lack of citizen control/ownership of the deliberative process.

3. How to achieve representativeness when citizen do not want to participate.

4. How to ensure accountability to the participants for the outcome of the deliberation when the deliberative process is only one input into the decision-making process or if the final decision is several years into the future or may not be taken at all.

5. How to build an infrastructure of civic deliberation within communities and public institutions. ${ }^{70}$

Abelson et al concluded that, overall, the public finds deliberative processes "stimulating and informative", but it is not known yet if they improve or even change decisions. ${ }^{70}$

In another systematic review, Gravel et al focus on the health professionals' perception of SDM to identify barriers and facilitators of implementing SDM in clinical practice. ${ }^{74}$ Reviewing 31 publications from different countries over the period 1990-2006, they are able to identify a number of barriers and facilitators that are related to factors classified under broad categories of knowledge, attitude, and behavior or external factors. The three most frequently reported barriers were the following: 1) time constraint; 2) perceived lack of applicability due to the characteristics of the patients; and 3) lack of applicability due to the clinical situation. ${ }^{74}$ The first one is 
behavior-related, whereas the other two are related to attitudes. The three most frequently reported facilitators are all related to the attitudes of the health professionals and include 1) motivation of health professionals to put SDM into practice; 2) the perception that putting SDM into practice would lead to improved patient outcomes; and 3) the perception that putting SDM into practice would lead to improved care processes. ${ }^{74}$ They also emphasize the need for targeting nurses and pharmacists in future studies of SDM because of their significant impact on the development of SDM. This systematic review is updated in 2008 by including ten new eligible studies, which confirms the previous results. ${ }^{75}$

A scoping review of the literature on public engagement over the period 1981-2006 undertakes to identify the gaps in this literature and take a first step toward the development of a set of "heuristics" for decision-makers concerned with the role of public input in priority setting and resource allocation. ${ }^{76}$ The vast majority of the reviewed publications (84\%) are said to have been published in or later than $1995 .{ }^{76}$ Following a detailed descriptive account of the variety of literature reviewed, they identify a number of key gaps. They include the lack of formal evaluation of public engagement exercises (as also pointed out by Abelson et $\mathrm{al}^{70}$ ), lack of studies to identify the role of the public in setting performance measures, the engagement of the disadvantaged or vulnerable populations and how it is done, lack of guidance about how to integrate the results of different public engagement processes with different forms of evidence, and no recognition that different methods might produce different impressions of the public's preferences. ${ }^{76}$ They also recognize, though implicitly, a few challenges and prospects in their review. They observe that "There seems to be no clear consensus in the literature on when public engagement should be sought, how it should be obtained, or how it might be incorporated by decision-makers into priority setting and resource allocation processes" ${ }^{76} \mathrm{Also}$, echoing the finding by White, ${ }^{77}$ they find a lack of concern with outcomes or the effectiveness of participation. As for the prospects, they find the use of multiple methods and the balancing of broad consultation with in-depth engagement using deliberative techniques promising. Also, they find the ability and willingness in seeking public input on an on-going basis as a promising way of public engagement in priority setting in comparison to on-off exercises. Finally, they find the extension of well-established approaches to public participation in environmental studies - such as the work by Rowe and Frewer ${ }^{78,79}$ - to priority setting and resource allocation valuable.

Interventions to improving health professionals' adoption of SDM is emphasized in the literature. ${ }^{80-82}$ Therefore, training programs in SDM for health professionals, like decision aids for the patients, have been implemented in different jurisdictions. Legare et al do an international scan of the programs aimed at enhancing health professionals' knowledge and skills in SDM implemented during 1996-2011. ${ }^{83}$ They identify 54 eligible programs from 14 countries in ten languages, with more than $60 \%$ of the programs taking place in the US, Canada, and the Netherlands. These programs targeted both licensed and prelicensure (in-training) physicians with a few programs designed for nurses and other health professionals. Most programs are found to be based on conceptual frameworks, of which the Ottawa Decision Support Framework was most frequently cited. ${ }^{83}$ They summarize their results succinctly as:

[...] our findings reveal that while health professional training programs in SDM are being steadily introduced world-wide, these programs vary greatly in how and what they deliver. In addition, evidence of their effectiveness is sparse. ${ }^{83}$

A systematic review of eleven randomized controlled trials studies on the effects of shared treatment decision-making on one or more of the following outcome measures: the degree of treatment adherence, patient satisfaction, well-being, and quality of life was carried out by Joosten et al, which they claim to be the first systematic review of its kind.$^{84}$ They find that the five studies, which were all related to physical health conditions and involved one decision or intervention session, reported no difference in the outcomes between SDM and the control group, one showed a positive effect for long-term but not for short-term, and the remaining five did report improved outcomes attributed to SDM, of which two were dealing with mental health conditions. The latter were dealing with intervention programs and longer-term decisions and/or chronic diseases and involved additional sessions compared to control treatments. An implicit challenge related to the lack of a direct measure for the quality of the SDM interventions in the studies as noted by the review is that:

Problems arise in interpreting the studies that yielded nega-

tive results - are these results attributable to failure of effec-

tive SDM, or to poor SDM technique or application? ${ }^{84}$

A dearth of randomized controlled studies of SDM interventions despite the evidence of their effectiveness in chronic illnesses and the growing clinical interest in such interventions is also noted as a problem. In fact, a recent thorough search by Duncan et al could find only two studies on the effects of SDM involving patients with mental health conditions. ${ }^{85}$ However, the authors cannot make any firm conclusions about the effects of SDM interventions for people with mental health conditions. 
In an overview of the implementation of SDM in the UK, Coulter et al identify 10 pre-requisites, which need to be in place for SDM to become the norm in clinical practice. ${ }^{86}$ They include: a) a favorable policy climate; b) appropriate regulatory, professional and legal standards; c) availability of decision supports, including information and tools; d) training for clinicians; e) patient champions; f) clinical champions; g) evidence of clinical and cost-effectiveness; h) metrics for monitoring progress; i) financial and other incentives; and j) a feasible implementation plan. ${ }^{86}$ In their judgment, most of these pre-requisites are in place in the UK. However, they point out the need for greater availability of staff training in the skills required for SDM, and financial and other incentives to overcome the barriers. ${ }^{86}$

Reviewing the experience of the implementation of SDM in the US, Frosch et al observe that SDM is advancing on many fronts including legislation to incorporate SDM into health care provision, research funding by public and private organizations, development of decision support interventions by academics and government organizations, increasing clinical trials of SDM and advocacy for SDM by professional organizations and social networks. ${ }^{28}$ They note finding implementation strategies that have "regulatory teeth" but stop short of being "interfering" in patient care, and taking the SDM movement to scale for SDM momentum to continue as concerns. However, they recognize the opportunity that SDM offers to bridge individual patient care with population health, and its contribution to patient-centered care, which is increasingly promoted by provider organizations. ${ }^{28}$

Church et al review a broad spectrum of literature to critically examine citizen participation in health decision-making within the context of Canada ${ }^{87}$ In their examination of both conceptual and empirical experiences, they draw on several provincial initiatives for citizen participation in health care settings to assert that "citizen participation in Canada has not progressed beyond the lower rungs of the participation ladder". ${ }^{87}$ They see "the imbalance of resources" among citizens, providers, and administrators that is manifested in "unequal interests" and "disproportionate information" as the root of the problem. ${ }^{87}$ Another major challenge is said to be:

[...] getting the providers to acknowledge the importance of patients' values in the medical decision-making process and developing strategies to incorporate this information into clinical decisions. ${ }^{87}$

Despite their critical approach, they point out that community health centers in Canada appear to offer greater opportunities for citizen participation.
Coulter $^{88}$ draws on three related sources ${ }^{89-91}$ to outline the key evidence in support of most promising patient engagement interventions. The study identifies three broad areas of attention - improving health literacy, helping patients make appropriate health decisions and improving the quality of care processes - in which specific interventions and their potential benefits are tabulated in detail. The author concludes by saying:

The important points to note are a) contrary to popular belief there is a great deal of published evidence on the likely effectiveness of patient engagement strategies and $b$ ) there is a compelling case for reviewing and, where necessary, adapting health care delivery and practice styles to enable active engagement of patients in planning and shaping their health care. ${ }^{88}$

\section{Evidence from individual studies}

In this section, an eclectic set of individual empirical studies that have used different methods in various health care settings and in different countries is reviewed. Such a review will give us a relatively reliable picture of the state of evidence to complement what was already portrayed in the above systematic reviews.

There are a number of studies on the implementation of public and patient involvement programs in the UK. An earlier study analyzes local participation in five mental health forums in Southern England. ${ }^{38}$ The study finds that roughly one-fifth of the intercessions could be regarded as "success", with another fifth as "response accepted", and more than $50 \%$ received "no response". It concludes "The mental health forums in Malville appeared to have a very limited impact upon the nature and direction of local mental health care provision", a result, which is attributed to the "political, managerial and clinical hegemony in the NHS". ${ }^{38}$ This sentiment is confirmed by another UK study that reflects on empirical findings from public consultation and user involvement in mental health and disability health services ${ }^{40}$ where it concludes "Despite the engagement of a significant number of HAs (Health Authorities) in public consultation through health panels, none agreed to be bound by their decisions". ${ }^{40}$ A similar conclusion is reached by Milewa et al in Southern England. ${ }^{41}$ The study in Southern England concludes:

A plethora of mechanisms for the consultation and involvement of local communities and groups has done little to weaken the influence exerted by health authority managers. ${ }^{38}$

Moreover, in reviewing the historical development of "patient and public involvement (PPI)" under the "New 
Labour" in the UK, Forster and Gabe ${ }^{21}$ find that despite strong emphasis on PPI,

The prominence of ideological reasons for the promotion of PPI in general [...] and the twists and turns of policy could partly explain the lack of conceptual clarity and stability and the inconsequent implementation. ${ }^{21}$

Still on the same theme, Martin and Finn study five pilot cancer-genetics projects in the British NHS where practitioners from various professions were brought together with service users to form collaborative teams. ${ }^{34}$ They find that "The situation in four of the sites, then, was one in which users felt they were not effectively incorporated into the wider professional teams running their pilots". ${ }^{34}$ In the fifth site partnership was successful, thanks to purposive selection of the users for their personal characteristics and skills, which they believe led to "the loss of the distinctive identity and contribution of the users". 34

Reporting on the results of a study in the three US hospitals where two SDM programs were implemented, HolmesRovner et $\mathrm{al}^{92}$ find that despite the "verbal" approval of the SDM programs by the participants (physicians, nurses, social workers, and administrators), physicians were not "spontaneous" to offer the programs to the patients. ${ }^{92}$ They observe that productivity and time pressure in the US health care severely constrain SDM implementation. An observation echoed years later by Frosch et al who try to elicit patients' beliefs about engaging in communication for SDM. ${ }^{93}$ They identify four overarching themes, which are said to impede the widespread implementation of SDM in routine practices, despite the desire voiced by the focus groups to collaborate with their physicians in making clinical decisions. The themes are:

[...] that patients feel compelled to conform to socially sanctioned roles in the clinical consultation; that physicians can be authoritarian; that patients work to fill information gaps; and that patients need to bring social support to the consultation. ${ }^{92}$

However, investigating the effect of discussion and deliberation on public's view of priority setting in health care, a study ${ }^{94}$ finds that:

$[\ldots]$ when people discuss complex issues related to setting

[...] priorities they are more reticent about the roles their views should play in determining priorities and more sympathetic to the role that health care managers play. ${ }^{94}$

In the two related studies in Canada, it is found that the members of community are not unanimous in their willingness and abilities to participate in health care decision-making, and that there is strong desire to be involved at the system and program levels, but much less at the patient level. ${ }^{95,96}$ Similarly, a study in Australia on the involvement of the general public in priority setting finds that the public has a strong preference for using their preferences to inform priority-setting decisions across broad health care programs and allocation of funds across populations, but prefer to leave decisions of prioritization of treatments and medical procedure to medical professionals and managers. ${ }^{97}$

Patient groups are involved in decision-making in some countries. A study from the Netherlands finds that patient groups or organizations have many opportunities to participate in formal health care decision-making, however, their "experiential knowledge" is seen to be undermined by professionalization and not valued as much by the established powerful decision-makers. ${ }^{98}$ Also, a study in the UK evaluates the experience of citizen juries deliberating on matters of health care policy, including health care rationing, and concludes:

Our experience of piloting citizens' juries suggest that given enough time and information, the public are willing and able to engage in debates about the allocation of finite resources for health care. ${ }^{99}$

Clearly, the empirical literature reports on a variety of methods of public participation or involvement, with some working better than others, depending on many contextual factors. A comparative study of deliberative public participation finds that although a "generic" participation method can be successfully implemented somewhat independent of context, contextual variables - such as the issue of interest, nature of decision, the culture of the sponsoring organization and attributes of the decision - play a fostering or an inhibiting role in its implementation. ${ }^{100}$

\section{Challenges and prospects: a summary}

Our review of the conceptualizations and implementations of deliberative democracy in health care settings has identified many challenges and some prospects. Some of the most common challenges and prospects or promises as identified in the literature are summarized in Table 2.

As the reviewed empirical evidence shows, the majority of challenges has to do with the practice of deliberative democracy in real health care settings. Admittedly, part of the problems and challenges are rooted in the ambiguity of the conceptions of deliberative democracy as perceived by the patients, health professional, administrators, and political 
Table 2 Some common challenges and prospect of deliberative democracy in health care

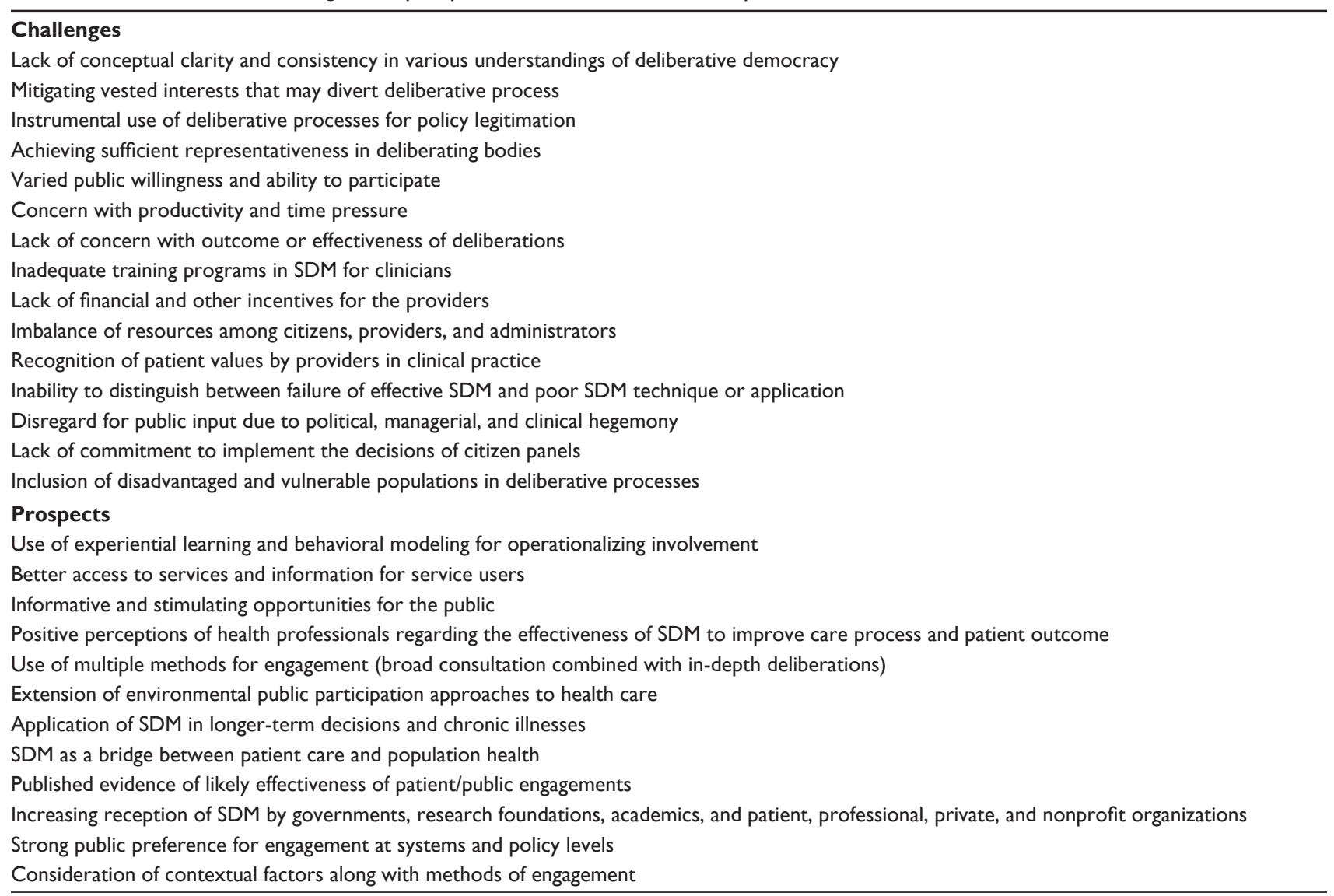

Abbreviation: SDM, shared decision-making.

leaders. However, many challenges arise from political, institutional, and professional resistance toward sharing decisionmaking power and lack of genuine interest in and openness to different ideas and values that bear upon the experience in the care process, clinical outcomes, and patient or public satisfaction. Lack of clarity on the underlying goals of public involvement and patient engagement on the part of policy makers contributes its own challenges. Cost-saving measures and rationing objectives should be clearly stated as such. In general, the public understands and is receptive to these objectives. However, when they are disguised in fashionable rhetoric about community engagement, patient choice, or accountable care, the public becomes confused. Engagement in deliberative processes is costly and, therefore, at crossroads with cost saving. Finally, almost all the deliberative initiatives implemented in different settings and places are isolated and fragmented experiences and not an integral part of a systemic approach to deliberative democracy and public engagement. While there are some attempts toward developing a systemic approach to deliberative democracy in political theory, ${ }^{17}$ we do not see a similar approach in health care.

\section{Conclusion}

Widespread dissatisfaction with the existing democratic systems that are not truly reflecting the views and choices of a vast majority of people and an increasing loss of trust in the elected governments based on a system of majority voting has encouraged democratic theorists to revisit the ideals of democracy and advocate for deliberative democracy as a system based on reasoned argument and consensus to replace the current system based on partisan votes. Developing practical models of deliberative democracy is at its early stage, and the evidence of its success so far is mixed. This has not stopped the promotion and testing of the idea in the complex systems of health care. Governments, academics, health advocates and citizen groups have promoted greater participation of the public in priority setting, and SDM in clinical practice. As a result, numerous participation and engagement projects have been implemented and are ongoing. Many of these projects have been reviewed in other reviews of the literature. The current review has drawn on a sizable literature on conceptualization and implementation of deliberative democracy in health care settings for the main purpose of identifying the 
current challenges as well as the promises of this significant undertaking. The challenges are real, yet the prospects are tentative and likely. However, the challenges are more or less known, whereas, the prospects become more evident as we experience with deliberative democracy in health care. Recognizing the challenges is the first step toward the feasible and successful implementation of the deliberative democracy paradigm in health care as elsewhere. Ultimately, the prospects for deliberative democracy in health care have to be seen in the light of the greater spread and deepening of such democracy in broader sociopolitical domains - where, respect for others, a sincere sense of community and an honest quest for improving the health and well-being of all would be the litmus test for our efforts in this regard.

\section{Acknowledgment}

I would like to thank Milad Fathi for his assistance during the initial search for literature.

\section{Disclosure}

The author reports no conflict of interest in this work.

\section{References}

1. Dryzek J, Ayirtman S, Niemeyer S, et al. Deliberative democracy. In: Bevir M, editor. Encyclopedia of Political Theory. Thousand Oaks, CA: SAGE Publications Inc.; 2010:353-357.

2. Dryzek J. Foundations and Frontiers of Deliberative Governance. Oxford: Oxford University Press; 2010.

3. Elster J. editor. Deliberative Democracy (Cambridge Studies in the Theory of Democracy). Cambridge: Cambridge University Press; 1998.

4. Ercan SA. Deliberative democracy. In: Phillips DC, editor. Encyclopedia of Educational Theory and Philosophy. Thousand Oaks, CA: SAGE Publications; 2014:214-216.

5. Fishkin J. When the People Speak. Oxford: Oxford University Press; 2011.

6. Cohen J. Deliberative democracy and democratic legitimacy. In: Hamlin A, Pettit P, editors. The Good Polity. Oxford: Blackwell; 1989:17-34.

7. Gutmann A, Thompson D. Why Deliberative Democracy? Princeton: Princeton University Press; 2002:3-7.

8. Smith G, Wales C. Citizens' juries and deliberative democracy. Polit Stud. 2000;48:51-65.

9. Miller D. Deliberative democracy and social choice. Polit Stud. 1992;XL (Special Issue):54-67.

10. Blattberg C. Patriotic, not deliberative, democracy. Crit Rev Int Soc Polit Philos. 1994;6(1):155-174.

11. Ryfe DM. Does deliberative democracy work? Annu Rev Polit Sci. 2005;8:49-71.

12. Warren M. Democracy and Associations. Princeton, NJ: Princeton University Press; 2001.

13. Sanders LM. Against deliberation. Polit Theory. 1997;25(3): 347-376.

14. Mansbridge J, Bohman J, Chambers S, et al. A systemic approach to deliberative democracy. In: Parkinson J, Mansbridge J, editors. Deliberative Systems: Deliberative Democracy at the Large Scale. Theories of Institutional Design. Cambridge, UK: Cambridge University Press; 2012:1-26.
15. Bohman J. The coming of age of deliberative democracy. J Polit Philos. 1998;6(4):400-425.

16. Fung A. Recipes for public spheres: eight institutional design choices and their consequences. J Polit Philos. 2003;11(3):338-367.

17. Thompson DF. Deliberative democratic theory and empirical political science. Annu Rev Polit Sci. 2008;11:497-520.

18. WHO. Declaration of Alma-Ata. International Conference on Primary Health Care, Alma-Ata, USSR; 6-12 September 1978. Geneva: World Health Organization; 1978.

19. Hubbard G, Kidd L, Donaghy E, McDonals C, Kearney N. A review about involving people affected by cancer in research, policy and planning and practice. Patient Educ Couns. 2007;65:21-33.

20. Forbat L, Hubbard G, Keaney N. Patient and public involvement: models and muddles. J Clin Nurs. 2009;18:2547-2554.

21. Forster R, Gabe J. Voice or choice? patient and public involvement in the National Health Service in England under New Labour. Int $J$ Health Serv. 2008;38(2):333-356.

22. Kelson M. User Involvement: A Guide to Developing Effective User Involvement Strategies in the NHS. London: College of Health; 1997.

23. NHS Executive. Patient and Public Involvement in the New NHS. Leeds: Department of Health; 1999.

24. NHS Executive. The NHS Plan: A Plan for Involvement, a Plan for Reform. London: Department of Health; 2000.

25. Beresford P, Croft S. Citizen Involvement: A Practical Guide for Change. Basingstoke: Macmillan; 1993.

26. Council of Europe. Recommendations of the Committee of Ministers of the Council of Europe on the Development of Structures for Citizen and Patient Participation in the Decision-Making Process Affecting Health Care. Strasbourg: Council of Europe; 2000.

27. Calnan M, Janoz H, Jolanta S. Citizen participation and patient choice in health reform. In: Saltman RB, Figueras J, Sakellarides C, editors. Critical Challenges for Health Reform in Europe. Buckingham: Open University Press; 1998:325-338.

28. Frosch DL, Moulton BW, Wexler RM, Holmes-Rovner M, Volk RJ, Levin CA. Shared decision making in the United States: policy and implementation activity on multiple fronts. Z. Evid. Fortbild. Qual. Gesundhwes. 2011;105:305-312.

29. Premier's Council on Health, Well-Being and Social Justice. A Framework for Evaluating Devolution. Toronto: The Task Force; 1994.

30. Nova Scotia's Blueprint for Health System Reform. Report of the Minister's Action Committee on Health System Reform. Halifax, NS: Department of Health; 1994.

31. Maxwell J, Rosell S, Pierre-Gerlier F. Giving citizens a voice in healthcare policy in Canada. BMJ. 2003;326:1031-1033.

32. Commonwealth Department of Health and Aged Care. National Health Strategy. Healthy Participation-Achieving Greater Public Participation and Accountability in the Australian Health Care System. Background Paper No 12, Commonwealth of Australia, Canberra; 1993.

33. NSW Department of Health. Community Consultation and Participation. Resource Kit for Area Health Service Managers and Project Leaders. State Health Publication No 980188; 1999.

34. Martin GP, Finn R. Patient as team members: opportunities, challenges and paradoxes of including patients in multi-professional healthcare teams. Sociol Health Illn. 2011;33(7):1050-1065.

35. Donovan JL, Coast J. Public participation in priority setting: commitment or illusion? In: Coast J, editor. Priority Setting: The Health Care Debate. Chichester: Wiley; 1996.

36. Calnan M. Citizens, users and health care. Eur J Public Health. 1997;7:1-2.

37. Tenbensel T. Virtual special issue introduction: Public participation in health policy in high income countries - a review of why, who, what, which, and where? Soc Sci Med. 2010;71:1537-1540.

38. Milewa T. Community participation and health care priorities: reflections on policy, theatre and reality in Britain. Health Promot Int. 1997;12(2):161-168.

39. Lomas J. Reluctant rationers: public input to health care priorities. J Health Serv Res Policy. 1997;2(2):103-111. 
40. Harrison S, Mort M. Which Champions? Which People? Public and User Involvement in Health Care as a Technology of Legitimation. Soc Policy Adm. 1998;32(1):60-70.

41. Milewa T, Valentine J, Calnan M. Community participation and citizenship in British health care planning: narratives of power and involvement in the changing welfare state. Sociol Health Illn. 1999;21(4):445-465.

42. Saltman RB, Figueras J. European Health Care Reform. Analysis of Current Strategies. Copenhagen: WHO Regional Publications, European Series, No 72; 1997:112. Available from: http:/www.euro.who.int/en/ about-us/partners/observatory/publications/studies/european-healthcare-reform.-analysis-of-current-strategies. Accessed April 25, 2015.

43. Arnstein S. A ladder of citizen participation. J Am Inst Plan. 1969;35: 216-224.

44. Finegold B. Citizen participation: a review of the issues. In: Rosen HM, Metsch JM, Levey S, editors. The Consumer and the Health Care System: Social and Managerial Perspectives. New York: Spectrum; 1997.

45. Emanuel EJ, Emanuel LL. Four models of the physician-patient relationship. JAMA. 1992;267(16):2221-2226.

46. Cahill J. Patient participation: a concept analysis. J Adv Nurs. 1996;24: 561-571.

47. Hanley B, Bradburn J, Barnes M, et al. Involving the public in NHS, Public Health and Social Care Research: Briefing Notes for Researchers, 2nd ed. Hampshire: INVOLVE; 2004.

48. Thompson AGH. The meaning of patient involvement and participation in health care consultations: a taxonomy. Soc Sci Med. 2007;64: 1297-1310.

49. Charles C, DeMaio S. Lay participation in health care decision making: A conceptual framework. J Health Polit Policy Law. 1993;18:881-904.

50. Deber RB, Baumann AO. Clinical reasoning in medicine and nursing: decision making vs problem solving. Teach Learn Med. 1992;4:140-146.

51. Deber RB, Kraetschmer N, Urowitz S, Sharpe S. Do people want to be autonomous patients? Preferred roles in treatment decision-making in several patient populations. Health Expect. 2007;10:248-258.

52. Tritter JQ, McCallum A. The snakes and ladders of user involvement: moving beyond Arnstein. Health Policy. 2006;76:156-168.

53. Marent B, Forster R, Nowak P. Conceptualizing Lay Participation in Professional Health Care Organizations. Adm Soc. 2015;47:827-850.

54. Luhmann N. Social Systems. Stanford, CA: Stanford University Press; 1995.

55. Carman K, Dardess P, Maurer M, et al. Patient and family engagement: a framework for understanding the elements and developing interventions and policies. Health Aff. 2013;32(2):223-231.

56. Haynes B, Haines A. Barriers and bridges to evidence based clinical practice. BMJ. 1998;317:273-276.

57. Barry MJ, Edgman-Levitan S. Shared decision making - the pinnacle of patient-centered care. $N$ Engl J Med. 2012;366(9):780-781.

58. Secretary of State for Health. Equity and Excellence. Liberating the NHS. London: The Stationary Office; 2010. Report No: Cm 7881. Quoted in Coulter et al [87], p 301.

59. Charles C, Gafni A, Whelan T. Shared decision-making in the medical encounter: What does it mean? (Or it takes at least two to tango). Soc Sci Med. 1997;44(5):681-692.

60. Charles C, Gafni A, Whelan T. Decision-making in the physician-patient encounter: revisiting the shared treatment decision-making model. Soc Sci Med. 1999;49:651-661.

61. Legare F, Wittman HO. Shared decision making: examining key elements and barriers to adoption into routine clinical practice. Health Aff. 2013;32(2):276-284.

62. Wagner EH, Barrett P, Barry MJ, Barlow W, Fowler FJ Jr. The effect of a shared decision-making program on rates of surgery for benign prostatic hyperplasia. Pilot results. Med Care. 1995;33:765-770.

63. O'Conner AM, Rostom A, Fiset V, et al. Decision aids for patients facing health treatment or screening decisions: systematic review. BMJ. 1999;319:731-734.
64. Scholl I, Loon MK-v, Sepucha K, Elwyn G, Legare F, Harter M. Measurement of shared decision making - a review of instruments. Z Evid Fortbild Qual Gesundhwes. 2011;105:313-324.

65. Moumjid N, Gafni A, Bremond A, Carrere M-O. Shared decision making in the medical encounter: are we all talking about the same thing? Med Decis Making. 2007;27:539-546.

66. Stacey D, Legare F, Pouliot S, et al. Shared decision making models to inform an interprofessional perspective on decision making: a theory analysis. Patient Educ Couns. 2010;80:164-172.

67. Parkinson JR. Deliberating in the Real World: Problems of Legitimacy in Deliberative Democracy. Oxford: Oxford University Press; 2006. Quoted in Mansbridge et al [14], p 6.

68. Abelson J, Eyles J, McLeod CB, et al. Does deliberation make a difference? Results from a citizens panel study of health goals priority setting. Health Policy. 2003;66:96-106.

69. Crawford MJ, Rutter D, Manley C, et al. Sustematic review of involving patients in the planning and development of health care. BMJ. 2002;325: $1-5$.

70. Abelson J, Forest P-G, Eyles J, et al. Deliberations about deliberative methods: issues in the design and evaluation of public participation processes. Soc Sci Med. 2003;57:239-251.

71. Renn O. Risk communication: Towards a rational discourse with the public. J Hazard Mater. 1992;29:465-519.

72. Webler T. "Right" discourse in citizen participation: an evaluative yardstick. In: Renn O, Webler T, Wiedelmann P, editors. Fairness and Competence in Citizen Participation: Evaluating Models for Environmental Discourse. Boston, MA: Kluwer Academic Press; 1995:35-86.

73. Beierle TC. Using social goals to evaluate public participation in environmental decisions. Policy Stud Rev. 1999;16(3-4):75-103.

74. Gravel K, Legare F, Graham ID. Barriers and facilitators to implementing shared decision-making in clinical practice: a systematic review of health professionals' perceptions. Implement Sci. 2006;16:1-12.

75. Legare F, Ratte S, Gravel K, Graham ID. Barriers and facilitators to implementing shared decision-making in clinical practice: Update of a systematic review of health professionals' perceptions. Patient Educ Couns. 2008;73:526-535.

76. Mitton G, Smith N, Peacock S, et al. Public participation in health care priority setting: a scoping review. Health Policy. 2009;91:219-228.

77. White D. Consumer and community participation: a reassessment of process, impact and value. In: Albrecht GL, Fitzpatrick R, Scrimshaw $\mathrm{SC}$, editors. The Handbook of Social Studies in Health and Medicine. Thousand Oaks: Sage Publications; 2000:465-480.

78. Rowe G, Frewer LJ. Evaluating public participation exercises: a research agenda. Sci Technol Human Values. 2004;29:512-556.

79. Rowe G, Frewer LJ. Public participation methods: a framework for evaluation. Sci Technol Human Values. 2004;25:3-29.

80. Kiesler DJ, Auerbach SM. Optimal matches of patient preferences for information, decision-making and interpersonal behaviour: evidence, models and interventions. Patient Educ Couns. 2006;61:319-341.

81. Legare F, Ratte S, Stacey D, et al. Interventions for improving the adoption of shared decision making by healthcare professionals. Cochrane Database Syst Rev. 2010;CD006732.

82. Legare F, St-Jacques S, Gagnon S, et al. Prenatal screening for Down syndrome: a survey of willingness in women and family physicians to engage in shared decision-making. Prenat Diagn. 2011;31: 319-326.

83. Legare F, Politi MC, Drolet R, et al. Training health professionals in shared decision-making: an international environmental scan. Patient Educ Couns. 2012;88:159-169.

84. Joosten EA, Defuentes-Merillas I, de Weert GH, et al. Systematic review of the effects of shared decision-making on patient satisfaction, treatment adherence and health status. Psychother Pschycosom. 2008;77:219-226.

85. Duncan E, Best C, Hagen S. Shared decision making interventions for people with mental health conditions. Cochrane Database Syst Rev. 2010;CD007297. 
86. Coulter A, Edwards A, Elwyn G, Thomson R. Implementing shared decision making in the UK. Z Evid Fortbild Qual Gesundhwes. 2011;105:300-304.

87. Church J, Saunders D, Wanke M, et al. Citizen participation in health decision-making: past experience and future prospects. J Public Health Policy. 2002;23(1):12-32.

88. Coulter A. Patient engagement - what works? J Ambul Care Manage. 2012;35(2):80-89.

89. Coulter A, Ellins J. Effectiveness of strategies for informing, educating, and involving patients. BMJ. 2007;335(7609):24-27.

90. Coulter A. Engaging patients in their healthcare. Picker Institute Europe. 2006. Available from: http:/www.pickereurope.org/wp-content/ uploads/2014/10/Engaging-patients-in-their-healthcare-how-is-the-UKdoing.pdf. Accessed June 11, 2015.

91. Coulter A. Engaging Patients in Healthcare. New York, NY: Mc GrawHill Education; 2011.

92. Holmes-Rovner M, Valade D, Orlowski C, Draus C, Nabozny-Valerio B, Keiser S. Implementing shared decision-making in routine practice: barriers and opportunities. Health Expect. 2000;3:182-191.

93. Frosch DL, May SG, Rendle KAS, Tietbohl C, Elwyn G. Authoritarian physicians and fear of being labeled 'difficult' among key obstacles to shared decision making. Health Aff. 2012;31(5):1030-1038.
94. Dolan P, Cookson R, Ferguson B. Effect of discussion and deliberation on the public's views of priority setting in health care: focus group study. BMJ. 1999;318:916-919.

95. Abelson J, Lomas J, Eyles J, Birch S, Veenstra G. Does the community want devolved authority? results of deliberative polling in Ontario. CMAJ. 1995;153(4):403-412.

96. Abelson J, Forest P-G, Eyles J, et al. Obtaining public input for health systems decision making: Past experiences and future prospects. Can Pub Adm. 2002;45(1):70-97.

97. Wiseman V, Mooney G, Berry G, Tang KC. Involving the general public in priority setting: experiences from Australia. Soc Sci Med. 2003;56:1001-1012.

98. van de Bovenkamp HM, Trappenburg MJ, Grit KJ. Patient participation in collective healthcare decision-making: the Dutch model. Health Expect. 2009;13(1):73-85.

99. Lenaghan J. Involving the public in rationing decisions. The experience of citizens juries. Health Policy. 1999;49(1-2):45-61.

100. Abelson J, Forest P-G, Eyles J, Casebeer A, Martin E, Mackean G. Examining the role of context in the implementation of a deliberative public participation experiment: results from a Canadian comparative study. Soc Sci Med. 2007;64:2115-2128.

\section{Publish your work in this journal}

The Journal of Healthcare Leadership is an international, peer-reviewed, open access journal focusing on leadership for the health profession. The journal is committed to the rapid publication of research focusing on but not limited to: Healthcare policy and law; Theoretical and practical aspects healthcare delivery; Interactions between healthcare and society and evidence-based practices;

\section{Dovepress}

Interdisciplinary decision-making; Philosophical and ethical issues; Hazard management; Research and opinion for health leadership; Leadership assessment. The manuscript management system is completely online and includes a very quick and fair peer-review system. Visit http://www.dovepress.com/ testimonials.php to read real quotes from published authors. 